\title{
AC 2007-2593: PREPARING MECHANICAL ENGINEERING STUDENTS FOR SENIOR DESIGN PROJECTS WITH ELECTRONICS COMPONENTS
}

\section{Scott Kiefer, Tri-State University}

Scott Kiefer is currently an Associate Professor of Mechanical Engineering at Tri-State

University. He received his B.S. in Mechanical Engineering from the University of Wisconsin at Platteville, and his M.S. and Ph.D. in Mechanical Engineering from North Carolina State University. 


\title{
Preparing Mechanical Engineering Students for Senior Design Projects with Electronics Components
}

\begin{abstract}
Many mechanical engineering students try to avoid having to work on senior design projects that include electronics because they feel like they are in over their heads. The attitude is understandable because most mechanical engineering students have very little opportunity to do any type of hands-on activities with electronics, and their graduation hinges upon completing their senior project. Most have taken one course in circuit analysis, but have never designed or built anything that includes any electronic components. This paper describes attempts to break down the stigma that mechanical engineering students often hold: "It is a job for the EE's."

For the past two years, Tri-state University has had successful senior design projects in mechanical engineering that included electronic components. Some of the projects have been with multi-disciplinary teams including electrical and computer engineering students, and some of the projects have been exclusively mechanical engineering students. Providing the mechanical engineering students with the necessary background to be successful with the projects has come from two different methods. The first was to require the students to take a prerequisite course in mechatronics, and the second was to complete basic electronics projects in the two-semester mechanical engineering senior design course itself. Both methods have proven to be effective, and often provided benefits after graduation to the students participating in the projects.
\end{abstract}

\section{Introduction}

More and more of today's mechanical engineers are doing work that requires them to have a strong background in electronics. With industries struggling to keep costs down by implementing more automation, there is a strong desire for mechanical engineers working in manufacturing positions to have hands-on experience with electronics and robotics. ${ }^{1}$ Manufacturing environments are not the only place mechanical engineers are required to have a strong background in electronics. Mechanical engineers in design positions are also finding microprocessors and electronic devices often must be included in the most cost effective design solutions. Many universities currently have entire research centers solely for the study and development of mechatronic and robotic devices because of the industry demand for the technology and for students with this background. ${ }^{2}$ Furthermore, Admissions Departments ${ }^{3}$ are getting more and more requests from prospective undergraduate students wondering what mechanical engineering programs have to offer in the field of robotics or mechatronics.

When they are ready to begin their senior design projects, it is not surprising that most mechanical engineering students feel unprepared to handle projects that include electronics because most mechanical engineering programs require very little background in electronics. For example, mechanical engineering students at Tri-State University receive a general introduction to electricity and magnetism in a physics courses, and take one basic circuit analysis 
class with no hands-on experience. ${ }^{4}$ Experience applying electronic applications to design projects is usually gained as "on the job training" after students leave the university.

Because of the growing need for undergraduate mechanical engineering students who are comfortable using electronics for design and manufacturing, the Mechanical Engineering Department at Tri-State University has made a concentrated effort to include opportunities for undergraduate mechanical engineering students to get experience using electronic devices in their design projects. For the past two years, the focus has been getting students prepared to participate in senior design projects with electronic components. Two different approaches have been used. The first was to require the students to take an elective course in mechatronics taught by the Mechanical Engineering Department before taking senior design. The second was to include eight weeks of hands-on electronic projects in the first semester of a two semester long senior design sequence.

\section{Elective Mechatronics Course}

The mechatronics course was taught in such a way that students taking it were not required to have any prior knowledge of electronics or programming, and the course relied almost entirely on active learning techniques using hands-on student project work. The course had been continuously evolving as an elective course for mechanical engineering students over a four year period. It was always offered as an elective course open to all majors, and it had been taught to a variety of students from different backgrounds. Although the mechatronics course was most often composed mainly of mechanical engineering students, it also included computer engineering students, engineering technology students, and even two faculty members.

\subsection{Weekly Projects}

The first ten weeks of the course involved the students working in groups of two or three to complete basic projects in mechatronics. Each week the students were given a handout detailing a project along with oral instructions and demonstrations on how to complete it. The students were then given one week to complete the project as a group. There was a designated meeting time later in the week that they could attend to get help from the instructor (or from other groups), and of course the students could also get help during the instructor's office hours. The project handouts were very detailed at the beginning of the semester, but as the students became more comfortable, directions were not as explicit. As the semester progressed and new sensors and actuators were introduced, students were required to find data sheets on their own and design and build circuits that were not explicitly given to them. When they got to the last few one-week projects, the students were simply given suggestions and were directed to use techniques similar to ones they had used in previous projects.

After completing each weekly project, each group was required to prepare a ten-minute PowerPoint presentation. When the class met the next week, two students were chosen at random to give their presentations. The students were not told before the class started which group would be presenting, and the entire group was graded according to the presentation of the group member that was chosen to present. This encouraged every student to not only make sure that they understood the material, but that the other members of their group also understood the material. 
Because this course was taught primarily in the Mechanical Engineering Department, most students had no experience programming microprocessors. To compensate for this lack of experience, the first one-week project of the course included an introduction to programming a microprocessor and included simple tasks in declaring variables, performing calculations, and using different types of data structures. Most of the students taking this course also had very little experience building electric circuits (if any at all), and many had never even seen a breadboard. Therefore, the second one-week project included some simple exercises using pushbutton switches, LEDs, an infrared emitting diode, and an infrared transistor. The coursework then progressed to include projects with RC circuits, voltage dividers, sevensegment displays, timing functions, analog to digital conversion, $\mathrm{H}$-bridges and motor control, digital logic, Hall-effect sensors, and frequency and sound control. A complete list of the weekly projects can be found below in table 1, and handouts for the projects are available on the author's website. ${ }^{5}$

\begin{tabular}{|c|}
\hline Mechatronics Weekly Projects \\
\hline 1) Programming the Microprocessor \\
\hline 2) Lights, Switches, and Infrared \\
\hline 3) Buttons, Timing, and Numeric Displays \\
\hline 4) Conversion Between Digital and Analog \\
\hline 5) Using Timing for A/D Conversion \\
\hline 6) Motor Control Using an H-Bridge \\
\hline 7) Measuring Motor Speed Using Hall-effect Sensors \\
\hline 8) Digital Logic \\
\hline 9) Frequency and Sound Production \\
\hline
\end{tabular}

Table 1: Mechatronics Weekly Projects

\subsection{Final Projects}

After completing the first ten weeks of simple projects, the students were feeling comfortable using the microprocessors with different sensors and actuators. They were also becoming very good at researching how to accomplish new activities on their own and were ready to apply what they had learned to more substantial projects. Consequently, they were given a final six-week project which required them to apply the knowledge they gained in conjunction with researching a new topic that they were not already familiar with. Obviously, the projects were not of the complexity of a senior design project, but they were good preparation and experience.

One example of a mechatronics final course project was to design and build a sumowrestling robot to compete in a contest with the other students in the course. The sumo- 
wrestling robots operated on the same principle as actual sumo-wrestlers-simply push the opponent out of the ring. The sumo-wrestling ring was marked with black tape on a white tile floor, and the students were required to come up with their own sensors for detecting the line and finding the other robot. They were not allowed to damage the other robot, but could use any other means to get the opponent out of the ring. In order to keep the Sumo-wrestling contest fair, there were a few simple rules. First, each group of students was required to begin with a Rokenbok toy vehicle (see figure 1) and was not allowed to change the motors or drive system. In addition, each group was given the same batteries to run the vehicle so they all would have the same power available. The students were also allowed to make whatever modifications they wanted to the vehicles as long as the total weight did not exceed two pounds (the vehicles got better traction with more weight). Third, they were not allowed to destroy the other team's vehicle. They could temporarily disable it, as long as no physical damage was done. Finally, the vehicle was required to be autonomous with no outside influence once the match had begun. For pictures of the actual robots and contest film, see the author's web site. ${ }^{6}$

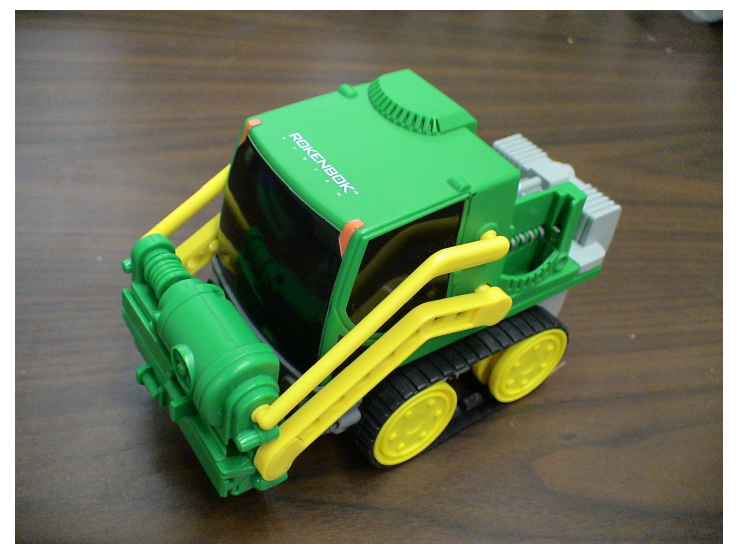

Figure 1: Original Rokenbok Toy Vehicle

\section{Hands-on Electronic Projects in Senior Design Course}

Because some students were not able to take the elective course in mechatronics, a special section of senior design was offered to accommodate senior design projects that included electronic components. To give the students the background they needed, projects similar to those in the mechatronics course were integrated into the course curriculum. These projects were in addition to the standard course material covered in senior design. The students who signed up for the special section were aware that there would be additional work involved in this section of senior design.

\subsection{Standard Senior Design Course Background}

Students at Tri-State University complete their senior design projects as part of a two semester sequence. The first semester is spent primarily on product design, product development, project management, and preliminary research. The second semester concentrates on the final design and construction of the project. Both semesters of the normal senior design 
course include milestone reports throughout the semesters, and have a final product development report at the end of the first semester and a complete design report at the end of the second semester.

\subsection{Senior Design with Electronics Background Added}

All the extra background information required for the electronics projects was added to the first semester of the senior design sequence. To keep the additions as simple as possible, most of the same weekly projects from the mechatronics course were also used (in a slightly condensed format) in the senior design course. For example, the programming introduction and introduction to lights, switches, and infrared were combined and completed in one week. The Hbridge motor control and motor speed measurement projects were also combined and into a one week project, and the frequency and sound production lab was dropped. The ten-minute Powerpoint presentations were still used each week, but the final projects from the mechatronics class were not included.

With the modifications of the mechatronics course in place, all of the background exercises were complete in seven weeks. This left nine weeks to cover the product design, product development, project management, and preliminary research normally done in the first semester of senior design. A bit of condensation was also done with the course material for product design and development, and the research activities were started concurrently as the background projects were being completed. With these changes, students in the senior design section that required the electronics background were up to speed after the first semester.

\section{Completed Senior Design Projects}

A few examples of senior design projects completed by students who were given the extra background in electronics are given in the following sections.

\subsection{Wind Tunnel Data Acquisition System}

The wind tunnel data acquisition system employed a strain gauge balance to measure lift, drag, and side-to-side forces along with the moment around each force's respective axis. The forces and moments were read as voltage changes across Wheatstone bridges composed of strain gauges within the sting balance. The voltage changes were interpreted by data acquisition software, correlated to equations of known force curves (which were created by the students), and then displayed for the wind tunnel operator. The design was implemented in the Tri-State University subsonic wind tunnel.

\subsection{Wire Diameter Measurement and Sorting Project}

The wire diameter measurement project was sponsored by a local industry that needed to check the diameter of braided cable. The cutting process the cable had undergone consisted of melting the strands of cable and pulling them apart. To insure quality, the diameter of the cable had to be checked following the cutting process to make sure it had not changed. The students designed and built a machine that would automatically inspect the wire, sort good from bad parts, and record the total number of good and bad parts completed per hour. 


\subsection{Paper Roll Alignment Project}

The paper roll alignment project included mechanical and electrical engineering students working together on a machine to automatically align rolls of newsprint that could weigh up to seven tons. The paper rolls were to be used in high-speed presses, so the paper was required to have a very precise (clean and square) edge. A small local company was providing edge trimming services; however, the precision alignment of a newsprint roll was taking up to 45 minutes. Tri-State University students designed an automatic alignment system which used a laser and a position sensing device (PSD) to align the center of the paper roll with the shaft of the cutting saw. The PSD provides data to the operator so that alignment can be completed in a fraction of the time.

\subsection{Fire-fighting Robot Project}

Several senior design groups have designed and built robots to compete in the Trinity College Fire-Fighting Robot Competition. ${ }^{7}$ The competition objective was to build an autonomous robot that could navigate through a small scale series of rooms and hallways, find a fire, and extinguish it. The first group was composed entirely of mechanical engineering students and competed in the senior division of the contest. In the senior division, rooms and hallway locations were made known before the competition. Two other groups of students competed in the expert division where the rooms and hallway location were not known before the competition. These groups both included electrical and computer engineering students working with the mechanical engineering students.

\section{Conclusions}

Mechanical engineering students are very capable of completing senior design projects that include electronic components if they are given a little additional experience in using electronic devices. The additional experience can be offered in the form of a separate course, or incorporated into an existing senior design course. Most students who are offered the opportunity to gain extra experience are grateful for the opportunity and are able to complete high quality projects.

The projects mentioned in this paper all fulfilled the expectations of the agency sponsoring the project. Even though one of the sponsoring companies changed the product specifications part way through the project, all the groups were able to deliver a working device that fulfilled all specifications (including the electrical components). The firefighting robot groups have also always been able to complete a functional robot in time for the competition, and have always finished in the top third of the schools entering the competition.

To measure student satisfaction, surveys were administered immediately following the student's completion of the mechatronics course. All of the students surveyed stated that their understanding of electronics had improved after taking the mechatronics course. Exactly half of the students stated that their understanding had "improved a lot", and half said their understanding had "improved some". Specific surveys were not administered after students had completed the senior design course, but standard course evaluations rated the overall quality of instruction in the class at a 4.5 on a 5 point scale. 
The successes obtained in giving mechanical engineering students extra experience in electronics has also carried over into student's activities after graduation. Two students who completed senior design projects with electronic components are currently pursuing graduate degrees in the field of mechatronics. Many other students have mentioned to the instructor that they have talked about their senior design projects in job interviews and feel it was a large factor in them being offered jobs. Several students have even told the author that they have become "the electronics guy" in their group of mechanical engineers a few months after graduation because they have knowledge that other mechanical engineers in their company do not.

\section{Bibliography}

1. J. Pinto, "Pinto's Points: How to Win in the Automation Business", ISA: The Instrumentation, Systems, and Automation Society, August 2005.

2. Carnigie Mellon University Robotics Center <www.ri.cmu.edu>, San Jose State University Mechatronics Labs $<$ www.engr.sjsu.edu/bjfurman/mechatronics $>$, UC Berkely Robotics Lab <www.robotics.eecs.berkeley.edu $>$.

3. K. Butler, Tri-State University Admissions Department, Personal Interview, November 2006.

4. Tri-State University Mechanical Engineering Curriculum, $<$ www.tristate.edu/engineering/mec/Curriculum/MECURR.pdf>, January 2007.

5. S. Kiefer, Personal Website, <www.tristate.edu/faculty/kiefer/MAE363.htm>, January 2007.

6. S. Kiefer, Personal Website, <www.tristate.edu/faculty/kiefer/robots/sumo.htm>, January 2007.

7. Trinity College Fire-fighting Robot Competition, <www.trincoll.edu/events/robot>, January 2007. 